\title{
Relationship of insulin resistance estimated by triglyceride glucose index to arterial stiffness
}

\author{
Ki-Bum Won ${ }^{1 *} \mathbb{D}$, Gyung-Min Park ${ }^{1 \dagger}$, Sang-Eun Lee ${ }^{2}$, In-Jeong $\mathrm{Cho}^{2}$, Hyeon Chang Kim³, \\ Byoung Kwon Lee ${ }^{4}$ and Hyuk-Jae Chang ${ }^{2^{*}}$
}

\begin{abstract}
Background: Insulin resistance (IR) is an important risk factor for subclinical atherosclerosis. This study evaluated the relationship between the triglyceride glucose (TyG) index, which is a simple and reliable surrogate marker for IR, and arterial stiffness.

Methods: This study included 2560 Korean subjects without a previous history of coronary artery disease, stroke, and malignancies who participated in a community-based cohort study. Arterial stiffness was measured using the brachial-ankle pulse wave velocity (baPWV).

Results: All participants were stratified into four groups based on the quartile of the TyG index. The prevalence of metabolic syndrome and diabetes significantly increased with increasing TyG index quartile. The mean baPWV was significantly different among all groups (group I [lowest]: $1421 \pm 242$ vs. group II: $1480 \pm 244$ vs. group III: $1534 \pm 260$ vs. group IV [highest]: $1575 \pm 279 \mathrm{~cm} / \mathrm{s} ; p<0.001)$. The TyG index values were correlated with $\operatorname{baPWV}(r=0.224, p<0.001)$. Multiple regression analysis showed that age $(\beta=0.410)$, male gender $(\beta=0.051)$, increased blood pressure $(\beta=0.266)$, and TyG index $(\beta=0.158)$ were associated with baPWV $(p<0.05$, respectively). TyG index was independently related to baPWV in both non-diabetics and diabetics.

Conclusions: The TyG index is independently associated with arterial stiffness in a relatively healthy Korean population.
\end{abstract}

Keywords: Insulin resistance, Arterial stiffness

\section{Introduction}

Cardiovascular (CV) disease is a major cause of morbidity and mortality. It is well-established that insulin resistance (IR) is associated with an increased risk of metabolic abnormalities, including hyperglycemia, dyslipidemia, and hypertension $[1,2]$. In addition, a number of studies have revealed that IR is one of the most important contributing factors to $\mathrm{CV}$ disease $[3,4]$.

\footnotetext{
* Correspondence: kbwon99@naver.com; hjchang@yuhs.ac

${ }^{\dagger}$ Ki-Bum Won and Gyung-Min Park contributed equally to this work.

${ }^{1}$ Division of Cardiology, Ulsan University Hospital, University of Ulsan College of Medicine, 877 Bangeojinsunhwando-ro, Dong-gu, Ulsan 44033, Republic of Korea

${ }^{2}$ Yonsei Cardiovascular Center, Yonsei University College of Medicine, 50 Yonsei-ro, Seodaemun-gu, Seoul 120-752, Republic of Korea Full list of author information is available at the end of the article
}

Recently, the triglyceride glucose (TyG) index was used as a simple and reliable surrogate marker of IR. Several studies reported that the TyG index is closely correlated with the homeostatic model assessment of insulin resistance (HOMA-IR) index, which has been traditionally used to measure IR [5-7]. However, there is a paucity of data on the relationship between the TyG index and subclinical atherosclerosis, especially arterial stiffness which has independent prognostic value for the risk of $\mathrm{CV}$ events. Moreover, although previous studies suggested the possibility of a somewhat different atherosclerotic change in diabetics compared to non-diabetics, data on the usefulness of TyG index on subclinical atherosclerosis according to diabetic status is currently unavailable. In clinical practice, brachial-ankle pulse wave velocity (baPWV) is used as a simple and reliable tool

(c) The Author(s). 2018 Open Access This article is distributed under the terms of the Creative Commons Attribution 4.0 International License (http://creativecommons.org/licenses/by/4.0/), which permits unrestricted use, distribution, and 
for the measurement of arterial stiffness because of its high reproducibility. Therefore, the present study evaluated the association between TyG index and arterial stiffness measured using baPWV in a relatively healthy Korean population.

\section{Methods}

\section{Participants}

This is a cross-sectional investigation analyzing baseline data collected for a prospective cohort study. We used the data of 2560 subjects who participated in baseline health examinations for a community-based cohort study in the Seoul area between April 2010 and November 2012. Subjects with a clinical history of cerebrovascular hemorrhage or infarction, neurological abnormalities, or malignancy were excluded from this study. The study protocol was approved by the local ethics committee of our institution, and informed consent for the procedure was obtained from each individual.

All blood samples were obtained after $8 \mathrm{~h}$ of fasting and analyzed for triglycerides, high-density lipoprotein (HDL) cholesterol, low-density lipoprotein (LDL) cholesterol, and glucose. Waist circumference was measured at the midpoint between the lower border of the rib cage and the iliac crest. The TyG index was calculated as $\ln$ [fasting triglycerides $(\mathrm{mg} / \mathrm{dL}) \times$ fasting glucose $(\mathrm{mg} / \mathrm{dL}) /$ 2]. Body mass index (BMI) was calculated as weight $(\mathrm{kg})$ / height $\left(\mathrm{m}^{2}\right)$. Metabolic syndrome was defined as when 3 or more of the following were present: (a) blood pressure $\geq 130 \mathrm{mmHg}$ systolic or $\geq 85 \mathrm{mmHg}$ diastolic or anti-hypertensive treatment; (b) HDL cholesterol $<40$ $\mathrm{mg} / \mathrm{dL}$ in males or $<50 \mathrm{mg} / \mathrm{dL}$ in females; (c) fasting triglycerides $\geq 150 \mathrm{mg} / \mathrm{dL}$; (d) abdominal obesity based on waist circumference $\geq 90 \mathrm{~cm}$ in males or $\geq 80 \mathrm{~cm}$ in females; and (e) impaired fasting glucose, defined as fasting glucose $\geq 100 \mathrm{mg} / \mathrm{dL}$ or established diabetes based on the American Heart Association/National Heart, Lung, and Blood Institute (AHA/NHLBI) definition [8]. Diabetes was defined as either fasting glucose $\geq 126 \mathrm{mg} / \mathrm{dL}$, a referral diagnosis of diabetes, or antidiabetic treatment.

\section{Measurement of baPWV}

All subjects abstained from beverages or caffeine-containing food for at least $45 \mathrm{~min}$ prior to baPWV measurement. After a subject had been resting in the supine position for at least $5 \mathrm{~min}$ in a quiet room, blood pressure and baPWV were measured using an automated waveform analyzer (Colin VP-2000, Colin Medical Instruments Corp., Komaki, Japan). Briefly, baPWV was measured in subjects' bilateral upper and lower extremities using plethysmographic sensor that simultaneously recorded blood pressure, an electrocardiogram, and heart sounds. baPWV was calculated as the length between arterial sites divided by time interval and was measured in both brachial and posterior tibial arteries. The higher value of baPWV measured on either side of each patient was used for analysis.

\section{Statistical analysis}

Continuous variables are expressed as the mean \pm standard deviation. Categorical variables are presented as absolute values and proportions. To compare the characteristics among the TyG index groups, one-way analysis of variance was used for continuous variables, and the $x^{2}$-test or Fisher's exact test was used for categorical variables, as appropriate. Correlational analysis between the TyG index and baPWV was performed using Pearson's correlation test. Univariate and multivariate linear regression analysis was performed to identify the association between independent variables and arterial stiffness. Variables with $p<0.05$ in the univariate analysis were considered confounding variables and entered into multivariate linear regression analysis. All statistical analyses were performed using the Statistical Package for the Social Sciences version 19 (SPSS, Chicago, Illinois), and a $p$-value of $<0.05$ was considered significant for all analyses.

\section{Results \\ Baseline characteristics}

Table 1 shows the clinical characteristics of the participants. All participants were stratified into four groups based on their TyG index levels. The mean levels of TyG index were $8.7 \pm 0.2,9.2 \pm 0.1,9.5 \pm 0.1$, and $10.0 \pm$ 0.3 in groups I (lowest), II, III, and IV (highest), respectively. There were significant differences in anthropometric indices, including BMI, waist circumference, and systolic and diastolic blood pressure. The prevalence of metabolic syndrome was 10.0, 19.1, 40.2, and $79.2 \%$ and that of diabetes was 7.2, 9.1, 17.2, and 30.6\% in groups I, II, III, and IV, respectively.

\section{Relationship between the TyG index and baPWV}

The mean baPWV significantly increased with increasing quartiles of the TyG index (group I [lowest]: $1421 \pm 242$ vs. group II: $1480 \pm 244$ vs. group III: $1534 \pm 260$ vs. group IV [highest]: $1575 \pm 279 \mathrm{~cm} / \mathrm{s} ; p<0.001$ ) (Fig. 1). The levels of the TyG index were significantly correlated with baPWV ( $r=0.224, p<0.001)$ (Fig. 2).

\section{Association between clinical variables and baPWV}

Univariate linear regression analysis showed that age $(\beta$ $=0.479, p<0.001)$, male gender $(\beta=0.137, p<0.001)$, abdominal obesity $(\beta=0.083, \quad \mathrm{p}<0.001)$, increased blood pressure $(\beta=0.391, p<0.001)$, decreased HDL $(\beta=0.057, p=0.004)$, smoking $(\beta=0.114, p<0.001)$, and TyG index $(\beta=0.224, p<0.001)$ were significantly associated with baPWV. Multivariate linear regression 
Table 1 Baseline characteristics

\begin{tabular}{|c|c|c|c|c|c|}
\hline & \multicolumn{4}{|c|}{ Quartile of the TyG index } & \multirow[t]{2}{*}{$p$} \\
\hline & ( (lowest) $(n=622)$ & $\|(n=658)$ & III $(n=640)$ & IV (highest) $(n=640)$ & \\
\hline Age, years & $59 \pm 8$ & $60 \pm 8$ & $61 \pm 8$ & $60 \pm 8$ & $<0.001$ \\
\hline Male, n (\%) & $147(23.6)$ & $179(27.2)$ & $224(35.0)$ & $292(45.6)$ & $<0.001$ \\
\hline Systolic blood pressure, $\mathrm{mmHg}$ & $119 \pm 14$ & $122 \pm 15$ & $124 \pm 15$ & $127 \pm 15$ & $<0.001$ \\
\hline Diastolic blood pressure, $\mathrm{mmHg}$ & $71 \pm 10$ & $73 \pm 9$ & $75 \pm 9$ & $77 \pm 10$ & $<0.001$ \\
\hline Heart rate, bpm & $65 \pm 9$ & $66 \pm 8$ & $68 \pm 10$ & $69 \pm 10$ & $<0.001$ \\
\hline Anti-hypertensive drugs, n (\%) & $195(31.4)$ & $278(42.2)$ & $295(46.1)$ & $326(50.9)$ & $<0.001$ \\
\hline Smoking, n (\%) & $114(18.3)$ & $134(20.4)$ & $188(29.4)$ & $259(40.5)$ & $<0.001$ \\
\hline $\mathrm{BMl}, \mathrm{kg} / \mathrm{m}^{2}$ & $23.8 \pm 2.9$ & $24.5 \pm 2.9$ & $25.3 \pm 2.9$ & $25.8 \pm 2.9$ & $<0.001$ \\
\hline Waist circumference, $\mathrm{cm}$ & $80 \pm 8$ & $83 \pm 8$ & $85 \pm 8$ & $87 \pm 9$ & $<0.001$ \\
\hline \multicolumn{6}{|l|}{ Laboratory } \\
\hline Total cholesterol, mg/dL & $191 \pm 33$ & $198 \pm 36$ & $203 \pm 37$ & $205 \pm 37$ & $<0.001$ \\
\hline Triglyceride, mg/dL & $66 \pm 13$ & $99 \pm 13$ & $133 \pm 21$ & $217 \pm 81$ & $<0.001$ \\
\hline $\mathrm{HDL}$ cholesterol, mg/dL & $64 \pm 15$ & $57 \pm 13$ & $51 \pm 13$ & $45 \pm 11$ & $<0.001$ \\
\hline LDL cholesterol, mg/dL & $114 \pm 29$ & $122 \pm 32$ & $128 \pm 34$ & $122 \pm 35$ & $<0.001$ \\
\hline Fasting glucose, mg/dL & $93 \pm 11$ & $96 \pm 11$ & $101 \pm 15$ & $115 \pm 31$ & $<0.001$ \\
\hline Creatinine, mg/dL & $0.76 \pm 0.19$ & $0.77 \pm 0.18$ & $0.79 \pm 0.18$ & $0.82 \pm 0.20$ & $<0.001$ \\
\hline Metabolic syndrome, n (\%) & $62(10.0)$ & $126(19.1)$ & $257(40.2)$ & $507(79.2)$ & $<0.001$ \\
\hline Diabetes mellitus, n (\%) & $45(7.2)$ & $60(9.1)$ & $110(17.2)$ & 196 (30.6) & $<0.001$ \\
\hline Anti-diabetic treatment, n (\%) & $41(6.6)$ & $56(8.5)$ & $96(15.0)$ & $154(24.1)$ & $<0.001$ \\
\hline TyG index & $8.7 \pm 0.2$ & $9.2 \pm 0.1$ & $9.5 \pm 0.1$ & $10.0 \pm 0.3$ & $<0.001$ \\
\hline
\end{tabular}

Values are given as the mean \pm standard deviation or number (\%)

$B M I$ body mass index, $H D L$ high-density lipoprotein, $L D L$ low-density lipoprotein, $T y G$ triglyceride glucose



Fig. 1 Comparison of baPWV according to TyG index group 


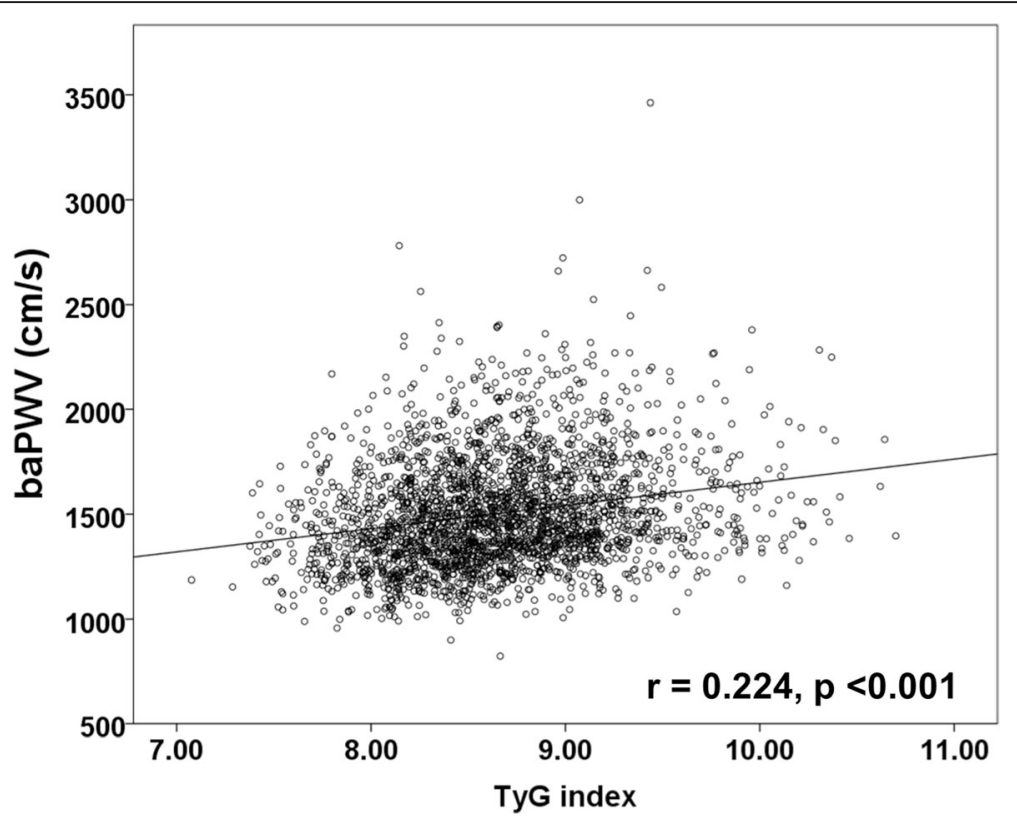

Fig. 2 Correlation between TyG index and baPWW

analysis showed that age $(\beta=0.410, \mathrm{p}<0.001)$, male gender $(\beta=0.051, p<0.043)$, increased blood pressure $(\beta=0.266$, $p<0.001)$, and TyG index $(\beta=0.158, p<0.001)$ were significantly associated with baPWV (Table 2).

\section{Relationship of TyG index to baPWV according to diabetic status}

Multiple linear regression models were analyzed to identify the association between TyG index and baPWV according to the established diabetic status. TyG index was independently related to the baPWV after consecutive adjustment for confounding variables in both nondiabetics and diabetics (Table 3 ).

Table 2 Association between clinical variables and baPWW

\begin{tabular}{lllll}
\hline & \multicolumn{3}{l}{ Univariate } & \multicolumn{2}{l}{ Multivariate } \\
\hline Age, years & $\beta$ & $p$ & $\beta$ & $p$ \\
Male & 0.479 & $<0.001$ & 0.410 & $<0.001$ \\
Abdominal obesity & 0.137 & $<0.001$ & 0.051 & 0.043 \\
Increased blood pressure & 0.083 & $<0.001$ & -0.032 & 0.065 \\
Decreased HDL & 0.057 & 0.004 & -0.026 & 0.140 \\
LDL > 130 mg/dL & 0.001 & 0.998 & & \\
Smoking & 0.114 & $<0.001$ & -0.021 & 0.396 \\
TyG index & 0.224 & $<0.001$ & 0.158 & $<0.001$
\end{tabular}

HDL high-density lipoprotein, $L D L$ low-density lipoprotein, $T y G$ triglyceride glucose

Increased blood pressure was defined as blood pressure $\geq 130 \mathrm{mmHg}$ systolic or $\geq 85 \mathrm{mmHg}$ diastolic or anti-hypertensive treatment

Decreased $\mathrm{HDL}$ was defined as $\mathrm{HDL}$ cholesterol $<40 \mathrm{mg} / \mathrm{dL}$ in males or $<50$ $\mathrm{mg} / \mathrm{dL}$ in females

\section{Discussion}

The main finding of present study was that the TyG index was significantly associated with arterial stiffness measured by baPWV after adjusting for other metabolic abnormalities. This result provides evidence that IR has a substantial role in subclinical atherosclerosis in a general population.

The homeostatic model assessment of insulin resistance (HOMA-IR) has been traditionally used to estimate IR $[9,10]$. However, insulin levels must be determined to calculate the HOMA-IR index. In South Korea, insulin levels are usually measured for established diabetics. Thus, HOMA-IR is an inconvenient parameter to identify IR in the general population. Recently, several studies reported

Table 3 Impact of TyG index on baPWV according to diabetic status

\begin{tabular}{lllll}
\hline & Non-diabetes & & Diabetes & \\
\hline & $\beta$ & $p$ & $\beta$ & $p$ \\
Model 1 & 0.171 & $<0.001$ & 0.131 & 0.004 \\
Model 2 & 0.161 & $<0.001$ & 0.126 & 0.006 \\
Model 3 & 0.134 & $<0.001$ & 0.125 & 0.009 \\
Model 4 & 0.137 & $<0.001$ & 0.122 & 0.011 \\
\hline
\end{tabular}

$\mathrm{HDL}$ high-density lipoprotein, $\mathrm{Ty} G$ triglyceride glucose

Definitions of increased blood pressure and decreased HDL are present in Table 2

Model 1 Adjusted for age

Model 2 Adjusted for age and gender

Model 3 Adjusted for age, gender, abdominal obesity, increased blood pressure, and decreased HDL

Model 4 Adjusted for age, gender, abdominal obesity, increased blood pressure, decreased $\mathrm{HDL}$, and smoking 
that the TyG index is closely correlated with HOMA-IR $[11,12]$. In addition, some studies suggested that the TyG index had better predictive value for IR than HOMA-IR $[6,13]$. Thus, the TyG index is being considered as a simple and useful surrogate marker of IR.

Early detection of atherosclerosis is important for preventing major $\mathrm{CV}$ events in the general population. In clinical practice, subclinical atherosclerosis is mostly evaluated at health check-ups with several tools, i.e., coronary artery calcium score (CACS), carotid intima-media thickness, plaque, and pulse wave velocity. Although IR might be a substantial risk factor for the development of $\mathrm{CV}$ disease, few studies evaluated the association between IR and subclinical atherosclerosis. In particular, data on the relationship between the TyG index and subclinical atherosclerosis have been limited. Irace et al. reported that the TyG index is strongly associated with carotid atherosclerosis, as assessed by Doppler ultrasonography, after adjusting for traditional CV risk factors [14]. ${ }^{14}$ Importantly, they emphasized that the TyG Index is better related to carotid atherosclerosis than HOMA-IR. Kim et al. also reported similar findings that the TyG index is more independently associated with the presence of coronary artery atherosclerosis assessed using CACS than is HOMA-IR in 4319 healthy Korean subjects [15]. In the CRONOS-ADM (Coronary $\mathrm{CT}$ angiography evaluation for clinical outcomes in asymptomatic patients with type 2 diabetes mellitus) registry, a higher TyG index is associated with increased risk of coronary artery stenosis in asymptomatic subjects with type 2 diabetes [16]. However, data on the association between the TyG index and arterial stiffness has been limited. The present study investigated the relationship between the TyG index and the arterial stiffness assessed by baPWV in Korean adults without a previous history of major $\mathrm{CV}$ events or malignancies. We also found that the TyG index was significantly associated with arterial stiffness after adjusting for confounding factors.

It is well-known that IR is a major characteristic of metabolic syndrome $[8,17]$. Additionally, despite the difference in the clinical features of diabetes according to ethnicity [18], IR has a pivotal role in the development of diabetes. Recently, a longitudinal study performed in 2900 non-diabetic adults indicated that the TyG index measured at a single point could be an indicator of the risk for incident diabetes [19]. Participants with TyG index $\geq 8.8$ regardless of obesity had a significantly high risk for diabetes in this study. We confirmed that the prevalence of metabolic syndrome and diabetes significantly increased with increasing quartiles of the TyG index in the present study. Considering that IR has a substantial role in metabolic abnormalities, IR might be an important target to reduce the risk of $\mathrm{CV}$ disease.
Although previous studies reported the different atherosclerotic change in diabetics compared to non-diabetics, we could identify that TyG index was useful IR parameter for predicting subclinical atherosclerosis in both non-diabetics and diabetics.

This study has some limitations. First, the present study includes only a Korean population. Second, we have not been able to eliminate the possible effects of underlying medications on subclinical atherosclerosis because of the observational design of this study. Third, the impact of IR on arterial stiffness may differ across different age groups. However, it was difficult to perform a sub-analysis of different age groups because none of the cohort study participants were very young. Fourth, we did not measure HOMA-IR because the examination of insulin levels is not usually included in general health check-ups at our institution. However, the close relationship between the TyG index and HOMA-IR was already well-established, as previous described. Fifth, we did not have information on the physical activity of participants. Finally, we did not evaluate the intra- and inter-observer correlation coefficient for the measurement of baPWV. However, it is well-known that the measurement of baPWV is simple and reliable for identifying arterial stiffness because of its high reproducibility [20, 21]. Despite these limitations, we could identify the independent impact of the IR estimated by the TyG index on arterial stiffness, which is an important marker of subclinical atherosclerosis.

In conclusion, the TyG index was independently associated with arterial stiffness measured by baPWV in a relatively healthy Korean population. This result suggested that that IR has a substantial role in subclinical atherosclerosis and might be an important target to prevent major $\mathrm{CV}$ disease.

\section{Abbreviations}

baPW: Brachial-ankle pulse wave velocity; BMI: Body mass index; CVD: Cardiovascular disease; HDL: High-density lipoprotein; HOMAIR: Homeostatic model assessment of insulin resistance; IR: Insulin resistance; LDL: Low-density lipoprotein; TyG: Triglyceride glucose

\section{Acknowledgements}

This study was supported by a grant from the Korea Health Technology R\&D Project through the Korea Health Industry Development Institute, funded by the Ministry of Health and Welfare, Republic of Korea (grant no. HI13C0715).

\section{Funding}

Not applicable.

\section{Availability of data and materials}

The datasets used and analyzed during the current study are available from the corresponding author on reasonable request.

Authors' contributions

All the authors listed in the manuscript participated in the design of the study and writing of the manuscript. KW and GP performed the statistical analysis. All the authors read and approved the final manuscript. 


\section{Ethics approval and consent to participate}

The study protocol was approved by our institution's ethics committee, and informed consent for the procedure was obtained from each individual.

\section{Consent for publication}

Not applicable.

\section{Competing interests}

The authors declare that they have no competing interests.

\section{Publisher's Note}

Springer Nature remains neutral with regard to jurisdictional claims in published maps and institutional affiliations.

\section{Author details}

'Division of Cardiology, Ulsan University Hospital, University of Ulsan College of Medicine, 877 Bangeojinsunhwando-ro, Dong-gu, Ulsan 44033, Republic of Korea. ${ }^{2}$ Yonsei Cardiovascular Center, Yonsei University College of Medicine, 50 Yonsei-ro, Seodaemun-gu, Seoul 120-752, Republic of Korea. ${ }^{3}$ Division of Preventive Medicine, Yonsei University College of Medicine, Seoul, South Korea. ${ }^{4}$ Division of Cardiology, Gangnam Severance Hospital, Yonsei University College of Medicine, Seoul, South Korea.

Received: 3 October 2018 Accepted: 15 November 2018 Published online: 24 November 2018

\section{References}

1. Bonora E, Kiechl S, Willeit J, Oberhollenzer F, Egger G, Targher G, Alberiche $\mathrm{M}$, Bonadonna RC, Muggeo M. Prevalence of insulin resistance in metabolic disorders: the Bruneck study. Diabetes. 1998:47:1643-9.

2. Bonora E, Targher G, Alberiche M, Bonadonna RC, Zenere MB, Saggiani F, Muggeo M. Intracellular partition of plasma glucose disposal in hypertensive and normotensive subjects with type 2 diabetes mellitus. J Clin Endocrinol Metab. 2001;86:2073-9.

3. Hanley AJ, Williams K, Stern MP, Haffner SM. Homeostasis model assessment of insulin resistance in relation to the incidence of cardiovascular disease: the San Antonio heart study. Diabetes Care. 2002;25:1177-84.

4. Bonora E, Kiechl S, Willeit J, Oberhollenzer F, Egger G, Meigs JB, Bonadonna $\mathrm{RC}$, Muggeo M. Insulin resistance as estimated by homeostasis model assessment predicts incident symptomatic cardiovascular disease in caucasian subjects from the general population: the Bruneck study. Diabetes Care. 2007;30:318-24.

5. Simental-Mendia LE, Rodriguez-Moran M, Guerrero-Romero F. The product of fasting glucose and triglycerides as surrogate for identifying insulin resistance in apparently healthy subjects. Metab Syndr Relat Disord. 2008;6: 299-304.

6. Vasques AC, Novaes FS, de Oliveira Mda S, Souza JR, Yamanaka A, Pareja JC, Tambascia MA, Saad MJ, Geloneze B. TyG index performs better than HOMA in a Brazilian population: a hyperglycemic clamp validated study. Diabetes Res Clin Pract. 2011;93:e98-100

7. Du T, Yuan G, Zhang M, Zhou X, Sun X, Yu X. Clinical usefulness of lipid ratios, visceral adiposity indicators, and the triglycerides and glucose index as risk markers of insulin resistance. Cardiovasc Diabetol. 2014;13:146.

8. Grundy SM, Cleeman JI, Daniels SR, Donato KA, Eckel RH, Franklin BA, Gordon DJ, Krauss RM, Savage PJ, Smith SC Jr, Spertus JA, Costa F. Diagnosis and management of the metabolic syndrome: an American heart association/national heart, lung, and blood institute scientific statement. Circulation. 2005:112:2735-52.

9. Wallace TM, Matthews DR. The assessment of insulin resistance in man. Diabet Med. 2002;19:527-34.

10. Cutfield WS, Jefferies CA, Jackson WE, Robinson EM, Hofman PL. Evaluation of HOMA and QUICKI as measures of insulin sensitivity in prepubertal children. Pediatr Diabetes. 2003:4:119-25.

11. Guerrero-Romero F, Simental-Mendia LE, Gonzalez-Ortiz M, MartínezAbundis E, Ramos-Zavala MG, Hernández-González SO, Jacques-Camarena $\mathrm{O}$, Rodríguez-Morán M. The product of triglycerides and glucose, a simple measure of insulin sensitivity. Comparison with the euglycemichyperinsulinemic clamp. J Clin Endocrinol Metab. 2010;95:3347-51.

12. Lee SH, Han K, Yang HK, Kim MK, Yoon KH, Kwon HS, Park YM. Identifying subgroups of obesity using the product of triglycerides and glucose: the
Korea National Health and nutrition examination survey, 2008-2010. Clin Endocrinol. 2015:82:213-20.

13. Lee $\mathrm{SH}$, Kwon HS, Park YM, Ha HS, Jeong SH, Yang HK, Lee JH, Yim HW, Kang MI, Lee WC, Son HY, Yoon KH. Predicting the development of diabetes using the product of triglycerides and glucose: the Chungju metabolic disease cohort (CMC) study. PLoS One. 2014;9:e90430.

14. Irace C, Carallo C, Scavelli FB, De Franceschi MS, Esposito T, Tripolino C, Gnasso A. Markers of insulin resistance and carotid atherosclerosis. A comparison of the homeostasis model assessment and triglyceride glucose index. Int J Clin Pract. 2013;67:665-72.

15. Kim MK, Ahn CW, Kang S, Nam JS, Kim KR, Park JS. Relationship between the triglyceride glucose index and coronary artery calcification in Korean adults. Cardiovasc Diabetol. 2017;16:108

16. Lee EY, Yang HK, Lee J, Kang B, Yang Y, Lee SH, Ko SH, Ahn YB, Cha BY, Yoon $\mathrm{KH}$, Cho $\mathrm{JH}$. Triglyceride glucose index, a marker of insulin resistance, is associated with coronary artery stenosis in asymptomatic subjects with type 2 diabetes. Lipids Health Dis. 2016;15:155.

17. NCEP. Executive summary of the third report of the national cholesterol education program (NCEP) expert panel on detection, evaluation, and treatment of high blood cholesterol in adults (adult treatment panel III). JAMA. 2001;285:2486-97.

18. Yoon KH, Lee JH, Kim JW, Cho JH, Choi YH, Ko SH, Zimmet P, Son HY. Epidemic obesity and type 2 diabetes in Asia. Lancet. 2006;368:1681-8.

19. Lee DY, Lee ES, Kim JH, Park SE, Park CY, Oh KW, Park SW, Rhee EJ, Lee WY. Predictive value of triglyceride glucose index for the risk of incident diabetes: a 4-year retrospective longitudinal study. PLoS One. 2016;11: e0163465.

20. Munakata M, Ito N, Nunokawa T, Yoshinaga K. Utility of automated brachial ankle pulse wave velocity measurements in hypertensive patients. Am J Hypertens. 2003;16:653-7.

21. Lee HS, Kim HL, Kim H, Hwang D, Choi HM, Oh SW, Seo JB, Chung WY, Kim $\mathrm{SH}$, Kim MA, Zo JH. Incremental prognostic value of brachial-ankle pulse wave velocity to single-photon emission computed tomography in patients with suspected coronary artery disease. J Atheroscler Thromb. 2015;22: $1040-50$

Ready to submit your research? Choose BMC and benefit from:

- fast, convenient online submission

- thorough peer review by experienced researchers in your field

- rapid publication on acceptance

- support for research data, including large and complex data types

- gold Open Access which fosters wider collaboration and increased citations

- maximum visibility for your research: over $100 \mathrm{M}$ website views per year

At BMC, research is always in progress.

Learn more biomedcentral.com/submissions 